\title{
Mapping and characterization of land subsidence in Beijing Plain caused by groundwater pumping using the Small Baseline Subset (SBAS) InSAR technique
}

\author{
M. L.Gao ${ }^{1,2, a}$, H. L.Gong ${ }^{1,2}$, B. B.Chen ${ }^{1,2}$, C. F. Zhou ${ }^{1,2}$, K. S. Liu ${ }^{1,2}$, and M. Shi ${ }^{1,2}$ \\ ${ }^{1}$ College of Resource Environment and Tourism, Capital Normal University, Beijing 100048, China \\ ${ }^{2}$ State Key Laboratory Incubation Base of Urban Environmental Processes and Digital Simulation, \\ Capital Normal University, Beijing 100048, China \\ a now at: Haidian, Beijing, China \\ Correspondence to: M. L. Gao (b-19890320@163.com)
}

Published: 12 November 2015

\begin{abstract}
InSAR time series analysis is widely used for detection and monitoring of slow surface deformation. In this paper, 15 TerraSAR-X radar images acquired in stripmap mode between 2012 and 2013 are processed for land subsidence monitoring with the Small Baseline Subset (SBAS) approach in Beijing Plain in China. Mapping results produced by SBAS show that the subsidence rates in the area of Beijing Plain range from -97.5 (subsidence) and to $+23.8 \mathrm{~mm} \mathrm{yr}^{-1}$ (uplift), relative to a presumably stable benchmark. The mapping result also reveals that there are the five subsidence centers formed by surface deformation spreading north to south east of the downtown. An uneven subsidence patten was detected near the Beijing Capital International Airpor, which may be related to loading of buildings and the aircraft.
\end{abstract}

\section{Introduction}

Land subsidence has become a hazard and could lead to serious problems especially in urban areas, related to city flooding (Ng et al., 2012), structural damages to buildings and other civilian infrastructures (Chaussard et al., 2013), including local subsurface water systems (Zhang et al., 2014). Consequently, subsidence monitoring in the urban area is necessary for safety, security, economic and planning reasons.

Subsidence in Beijing was first detected in the 1960s and has progressed in several areas for decades. The subsidence is mainly caused by intense groundwater extraction according to previous studies (Chen et al., 2014; Hu et al., 2014). Ground surface deformation can be observed through the InSAR techniques, which greatly facilitate the monitoring of the land subsidence in metropolitan areas (Kagawa and Furuno, 2010; Aobpaet et al., 2013). InSAR time-series methods such as PS-InSAR and Small Baseline methods have been applied to study subsidence in Beijing (Zhang et al., 2011; Gu et al., 2014). Chen et al. (2011) concluded that seasonal and inter-annual variation of groundwater draw- downs have resulted in an uneven spatial and temporal distribution of subsidence, with a maximum subsidence rate of about $-41.08 \mathrm{~mm} \mathrm{yr}^{-1}$.

This paper presents ground deformation results based on SBAS processing of 15 TerraSAR-X images covering the eastern area of the Beijing Plain, China. We processed the SLC (single look complex) images using the Stanford Method for Persistent Scatterers (StaMPS) processing software to determine the line-of-sight (LOS) displacements (native valued LOS displacements represent an increase in range and subsidence in this paper) and subsidence rates. We present the mapped subsidence rates and describe the characteristics of the subsidence in the study area.

\section{Study area and data description}

The study area is the Beijing Plain area (centered at $39^{\circ} 58^{\prime} 37^{\prime \prime} \mathrm{N}, 116^{\circ} 42^{\prime} 11^{\prime \prime} \mathrm{E}$ ) in the city of Beijing with as area of about $1900 \mathrm{~km}^{2}$ (Fig. 1). In this area, the elevation ranges from 20 to $40 \mathrm{~m}$, and there are many buildings and other civilian infrastructure. 


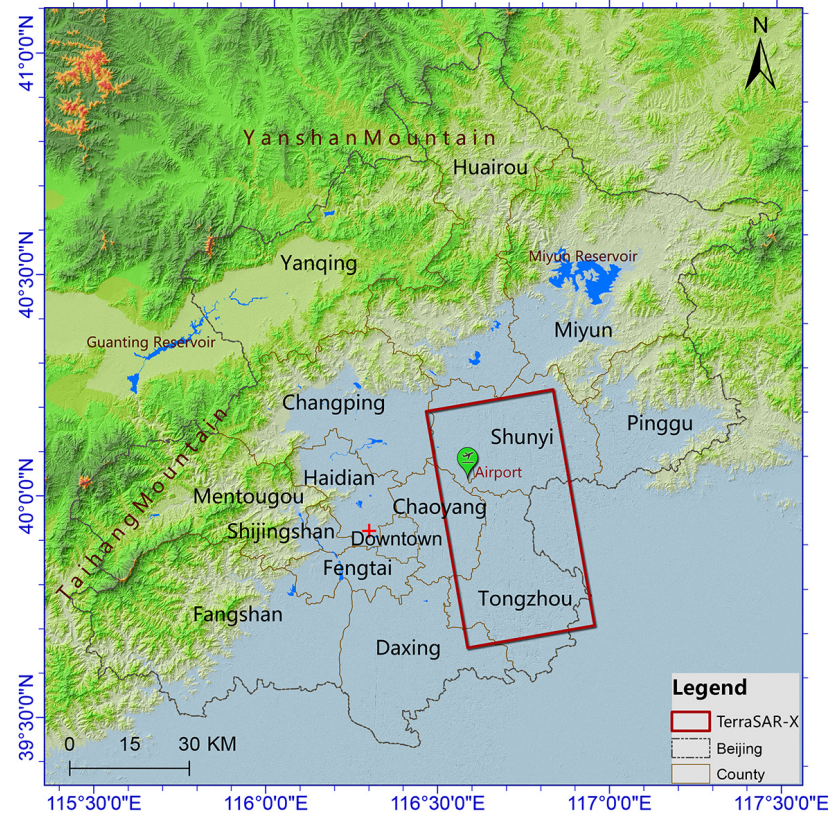

Figure 1. Map of the study area, Beijing Plain, China. The red box in the figure represents the coverage of the TerraSAR-X stripmap which covers an area of more than $1900 \mathrm{~km}^{2}$. The blue polygons are water bodies. The red cross symbol represents the location of the referenced M1 benchmark.

The 15 SLC ascending orbit, stripmode images have an azimuth resolution of $3.3 \mathrm{~m}$, and range resolution of $2.0 \mathrm{~m}$. The images were acquired over Beijing during the period of January 2012 and November 2013. The ASTER GDEM V2 product with 1 arcsec geographical resolution $(30 \mathrm{~m})$ was used as the external DEM in the InSAR process.

\section{Time-series InSAR analysis}

The SBAS analysis relies on a subset of interferogram pairs that were created with small temporal (over short time intervals) and geometrical baselines to limit decorrelation noise. The noise is further reduced by applying range and azimuth filters, and spatial multi-looking. In this paper, we performed the SBAS approach on the dataset using the StaMPS/MTI toolkit. The candidate pixels are identified in the same way as PS pixels (Hooper et al., 2007), based on the spatial correlation of the phase. A subset of 30 interferogram pairs were formed temporal and geometrical baselines less than 200 days and $500 \mathrm{~m}$, respectively, with an coherence threshold of 0.7. Phase unwrapping used a statistical cost approach.

\section{Results and discussion}

More than 220000 sufficiently coherent pixels were identified, processed from more than 2600000 candidate pixels. The mean LOS deformation rates (unit: $\mathrm{mm} \mathrm{yr}^{-1}$ ) were de-

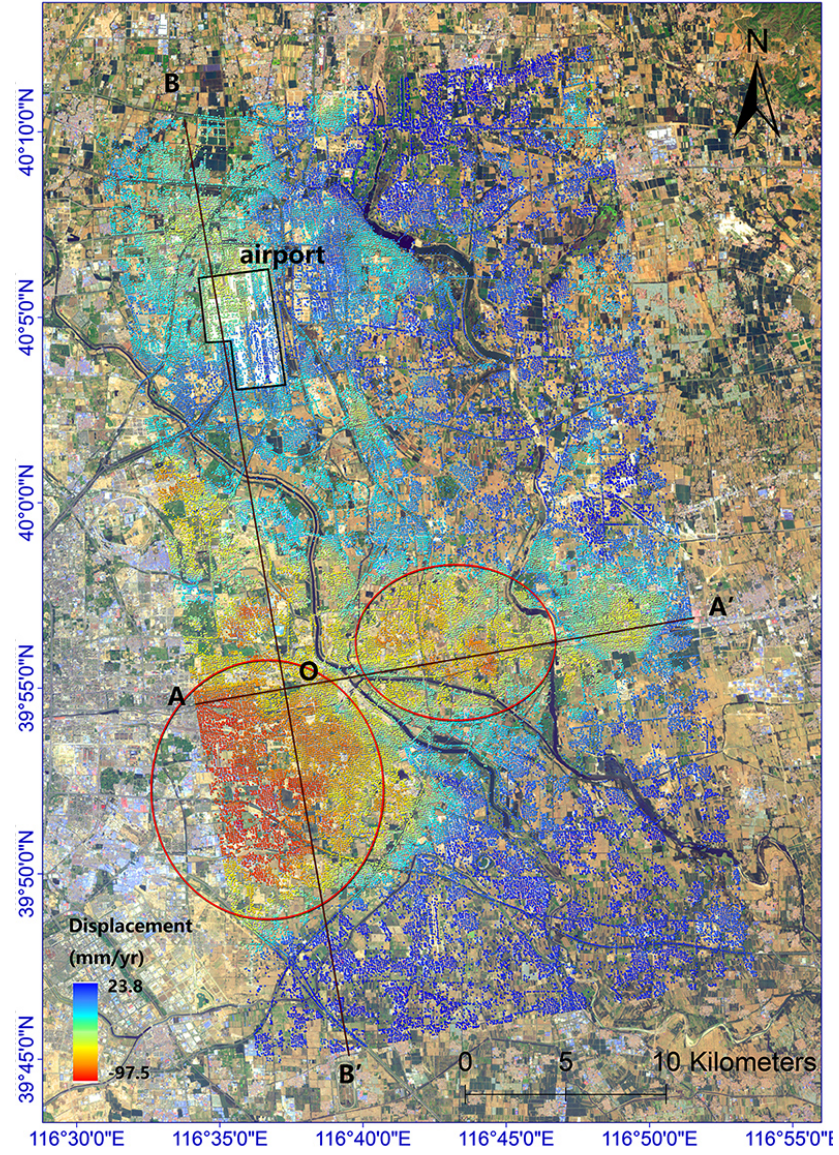

Figure 2. Mean LOS subsidence rates $\left(\mathrm{mm} \mathrm{yr}^{-1}\right)$ spatial distribution. Red and blue areas represent subsidence and uplift relative to the referenced point $\mathrm{M} 1$, respectively. Profile $\mathrm{A}-\mathrm{A}^{\prime}$, which is perpendicular to profile $\mathrm{B}-\mathrm{B}^{\prime}$, goes through the two subsidence areas (marked as red circles), and intersects the profile $\mathrm{B}-\mathrm{B}^{\prime}$ at $\mathrm{O}$. The black box represents the location of Beijing Capital International Airport.

rived from the unwrapped time-series phases using linear least squares. The results are relative to the benchmark M1 (as shown in Fig. 1). M1 is a levelling benchmark situated in a relatively stable area.

Figure 2 shows the mean LOS subsidence rate $\left(\mathrm{mm} \mathrm{yr}^{-1}\right)$ estimations. For coherent pixel from January 2012 to November 2013, the deformation rates range from -97.5 to $+23.8 \mathrm{~mm} \mathrm{yr}^{-1}$, relative to the benchmark M1. However, because no uplift is expected in this area, if we consider that M1 could be subsiding, then uplift areas shown in blue on Fig. 2 could be subsiding slower than M1. In this case, the maximum subsidence rate in eastern Beijing could be about $121.3 \mathrm{~mm} \mathrm{yr}^{-1}$.

As can be seen from the Fig. 2, fewer coherent pixels are evident in the non-urbanized rural areas and croplands in the east. Two main subsidence areas and several other subsidence features of smaller extent have formed since the 

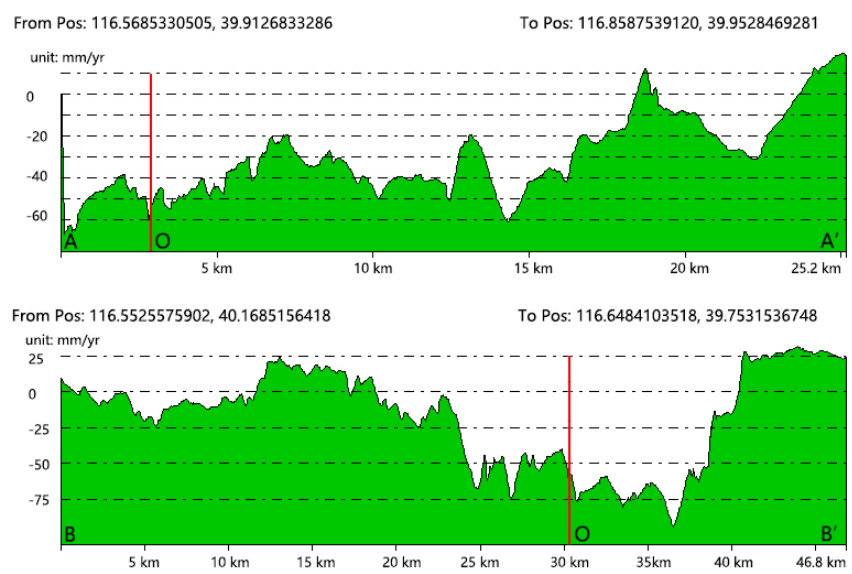

Figure 3. Subsidence rates along profile $\mathrm{A}-\mathrm{A}^{\prime}$ and profile $\mathrm{B}-\mathrm{B}^{\prime}$ shown in Fig. 2. The profiles intersect at the point $O$. (Note: negative values indicate subsidence.)

1990s. Figures 2 and 3 show that profile $\mathrm{A}-\mathrm{A}^{\prime}$ intersects the two main subsidence areas, and a smaller subsidence features, while profile $\mathrm{B}-\mathrm{B}^{\prime}$ intersects the southern subsidence area and two smaller subsidence features, including one at the airport. The settlements along the profile $\mathrm{A}-\mathrm{A}^{\prime}$ have extended and connected to one huge subsidence area. The subsidence in this area has been attributed to the exploitation of groundwater, as the previous studies concluded. However, we also detected subsidence near the Beijing Capital International Airport with ranging from -26.2 to $13.6 \mathrm{~mm} \mathrm{yr}^{-1}$. The T1 and T2 terminals constructed in the early 1990s appear to be subsiding slightly with respect to the surrounding areas, while the T3 terminal built in 2008 is uplifting relative to M1. We consider that subsidence at the airport is probably due to dynamic loading of aircraft takeoffs and landings and the static loading of the large buildings.

\section{Conclusions}

The SBAS technique was used with 15 TerraSAR-X SLC images to detect and characterize subsidence on the eastern Beijing Plain. Deformation measured during the period 2012 2013, show subsidence in two main areas and several other areas of smaller extent. The maximum subsidence rate was $-97.5 \mathrm{~mm} \mathrm{yr}^{-1}$. Uplift was also measured with a maximum rate of $+23.8 \mathrm{~mm} \mathrm{yr}^{-1}$. We believe that the subsidence is mainly caused by the exploitation of groundwater. Uneven subsidence was detected near the of the Beijing Capital International Airport location, which may be caused by surface loading of buildings and the arcraft, apart from the groundwater depression cones. Further work is planned to evaluate subsidence near the airport, and other ground-based geodetic surveys are planned to validate these results for the Beijing Plain.
Acknowledgements. The provision of the Doris and StaMPS for data processing by TUDelft is gratefully acknowledged.

\section{References}

Aobpaet, A., Cuenca, M. C., Hooper, A., and Trisirisatayawong, I.: InSAR time-series analysis of land subsidence in Bangkok, Thailand, Int. J. Remote Sens., 34, 2969-2982, doi:10.1080/01431161.2012.756596,2013.

Chaussard, E., Amelung, F., Abidin, H., and Hong, H.: Sinking cities in Indonesia: ALOS PALSAR detects rapid subsidence due to groundwater and gas extraction, Remote Sens. Environ., 128, 150-161, doi:10.1016/j.rse.2012.10.015, 2013.

Chen, B. B., Gong, H. L., Li, X. J., Lei, K. C., Zhang, Y. Q., Li, J. W., Gu, Z. Q., and Dang, Y. A.: Spatial-temporal characteristics of land subsidence corresponding to dynamic groundwater funnel in Beijing Municipality, China, Chinese Geogr. Sci., 21, 753-64, doi:10.1007/s11769-011-0509-6, 2011.

Chen, B. B., Gong, H. L., Li, X. J., Lei, K. C., Ke, Y. H., Duan, G. Y., and Zhou, C. F.: Spatial correlation between land subsidence and urbanization in Beijing, China, Nat. Hazards, 75, 2637-2652, doi:10.1007/s11069-014-1451-6, 2014.

Gu, Z. Q., Gong, H. L., Zhang, Y. Q., Lu, X. H., Wang, S., Wang, R., and Liu, H. H.: Research on Monitoring Land Subsidence in Beijing Plain Area Using PS-InSAR Technology. Spectrosc. Spect. Anal., 34, 1898-1902, 2014.

Hooper, A., Segall, P., and Zebker, H.: Persistent scatterer interferometric synthetic aperture radar for crustal deformation analysis, with application to Volcán Alcedo, Galápagos, J. Geophys. Res., 112, B07407, doi:10.1029/2006JB004763, 2007.

Hu, B., Wang, H. S., Sun, Y. L., Hou, J. G., and Liang, J.: LongTerm Land Subsidence Monitoring of Beijing (China) Using the Small Baseline Subset (SBAS) Technique, Remote Sens., 6, 3648-3661, doi:10.3390/rs6053648, 2014.

Kagawa, A. and Furuno, K.: Land subsidence monitoring system in the southeast part of Kanto groundwater basin, Japan, in: Land Subsidence, Associated Hazards And the Role Of Natural Resources Development, Proceedings of EISOLS 2010, Querétaro, Mexico, 17-22 October 2010, IAHS Publ. 339, 339-344, 2010.

Ng, A. H.-M., Ge, L. L., Li, X. J., Hasanuddin, Z., Abidin, Andreas, H., and Zhang, K.: Mapping land subsidence in Jakarta, Indonesia using persistent scatterer interferometry (PSI) technique with ALOS PALSAR, Int. J. Appl. Earth Obs., 18, 232 242, doi:10.1016/j.jag.2012.01.018, 2012.

Zhang, X. D., Ge, D. Q., Ma, W. Y., Zhang, L., Wang, Y., and Guo, X. F.: Study the Land Subsidence Along Jinghu Highway (Beijing-Hebei) Using Ps-Insar Technique, in: Geoscience and Remote Sensing Symposium (IGARSS), 2011 IEEE International, 24-29 July 2011, Vancouver, BC, IEEE, 1608-1611, doi:10.1109/IGARSS.2011.6049538, 2011.

Zhang, Y. Q., Gong, H. L., Gu, Z. Q., Wang, R., Li, X. J., and Zhao, W. J.: Characterization of land subsidence induced by groundwater withdrawals in the plain of Beijing city, China, Hydrogeol. J., 22, 397-409, 2014. 